\title{
Influence of Specific AR Capabilities on the Learning Effectiveness and Efficiency
}

\author{
Dragoş Daniel Iordache, Costin Pribeanu, Alexandru Balog \\ National Institute for Research and Development in Informatics - ICI Bucharest, \\ Mareşal Averescu Blvd., No. 8-10, Bucharest 011455, Romania, \\ iordache@ici.ro,pribeanu@ici.ro, alexb@ici.ro
}

\begin{abstract}
Augmented reality (AR) is a promising technology for improving the applicative and comprehension skills of students. The ARiSE project developed an Augmented Reality Teaching Platform (ARTP) for secondary schools. A Chemistry learning scenario was implemented that is based on the interaction paradigm "building with guidance". This study aims at assessing the extent to which specific capabilities of the ARTP support the understanding of Chemistry concepts as well as their contribution to the perceived utility. The results of a multiple-regression analysis show that the specific features of the Chemistry scenario enable students to better understand the subject matter with less effort in learning. Overall, the interaction paradigm proved to have a positive influence on the effectiveness and efficiency of the learning process.
\end{abstract}

Keywords: perceived usefulness, learning effectiveness, learning efficiency, augmented reality, e-learning.

\section{Introduction}

AR can enhance the learner's perception of a real environment, unlike other computer-based interactive technologies that draw users away from the real world and focus their attention onto a screen (Chen \&Tsai, 2012). Thus, AR is a promising technology for improving the practical and comprehension skills of students and supporting the learning and teaching process in educational contexts.

The Augmented Reality Teaching Platform (ARTP) was developed in the framework of the ARiSE project (Wind, Riege \& Bogen, 2007). ARTP consists in three research prototypes (applications), implementing various learning scenarios based on different interaction paradigms. The second prototype implemented a Chemistry scenario.

The interaction paradigm was "building with guidance" and was targeted at understanding the periodic table of Chemical elements, the structure of atoms / molecules, and chemical reactions. There are typical AR capabilities, such as: 3D visualization, animation, vocal interface for learning and guidance, and haptic feedback. There are also some specific features for this scenario: augmentation of the atom structure, building a molecule from atoms, and simulation of chemical reactions.

The purpose of this study is twofold: (a) to evaluate the extent to which these specific capabilities of the ARTP are supporting the understanding and learning of Chemistry concept (b) to analyze the relations between the ARTP features and two variables related to the perceived utility: effectiveness and efficiency of the learning process.

The rest of this paper is organized as follows. In the next section we present related work in AR-based learning. In Section 3 we describe the method, including the rationale for the evaluation instrument. The results of this study are presented in section 4 . The paper ends with conclusion and future work.

\section{Related Work}

\subsection{AR-based learning}

Augmented reality (AR) is a mix between the real world and virtual reality (VR). AR offers new opportunities for teaching and education, since students are experiencing various difficulties with learning and understanding Chemistry. One reason might be the difficulty to imagine the spatial structure of atoms and molecules.

AR environments are able to provide a valuable set of learning experiences when applied in teaching geometry and spatial relationships between molecule structures (Kaufman, 2004; Chen, 2006). Such studies tried to benefit from the advantage of AR to help the visualization of abstract concepts in a more intuitive way which in turn could lead to an improvement in student's comprehension.

As a result of a study about the impact of an augmented reality system on students' motivation for a visual art course, Di Serio et al (2012) conclude that the positive impact of AR on motivation leads students to achieve higher 
levels of engagement in the learning activities with less cognitive effort.

Fjeld et al. (2007) built an application that is using a tangible user interface for education of organic Chemistry (augmented Chemistry) aiming to increase the learning effectiveness. In their study learning effectiveness and user acceptance of the augmented Chemistry was compared with the ball-and-stick model. Results in learning effectiveness were almost the same for both learning environments. User preferences showed stronger differences and they decided to focus mainly on improving these aspects. The re-designed augmented Chemistry system was then compared to the old system via a qualitative user study, which showed an improvement in subjective opinions on the system's ease of use and ease of learning (Maier et al., 2009).

The studies carried on by Medina et al. (2007) tried to explain how AR technology helps students learn biochemistry. The results of experiments showed that AR was able to facilitate biochemistry learning and students enjoyed the process of interacting with AR.

Sankaranarayanan et al. (2003) described an application of augmented reality mixing a physical molecular model with computer graphics. Their system has three major parts: augmented reality (AR), a voice command interface and force feedback. Physical manipulation appeared to provide a natural and intuitive method to support interaction between molecules. The combination between the physical model and computer graphics through augmented reality attempted to take advantage from each environment: the physical and the virtual.

According to Chen \& Wang (2008), AR helps in bridging the gap between the theoretical knowledge acquired through analytical activities (such as reading text-books and listening to lectures) and the practical experience gained from constructive activities.

Several authors highlighted the benefits of using AR to support new learning paradigms, such as: drawing people's attention, enabling students to discover knowledge by themselves, providing a sense of spatial feeling, allowing users to use hands in a direct manipulation with real objects, enables experiential learning, social or collaborative learning, gives a sense of presence and is interactive (Chen, 2006; Liu et al., 2007).

\subsection{Previous work}

An evaluation instrument was developed in the framework of the ARiSE project that was targeting several factors of interest for e-learning systems, such as perceived ease of use, perceived utility, perceived enjoyment, and the intention to use (Pribeanu, Balog \& Iordache, 2008). The questionnaire includes both quantitative (answers to 28 closed items) and qualitative data (answers to 2 open questions).

The quantitative data was further used to estimate the causal relations between various factors influencing the intention to use ARTP (Balog \& Pribeanu, 2010). Although this structural model was useful to test several hypotheses the variance explained was small.

The qualitative data was also analyzed to take a closer look on positive and negative aspects related to the pedagogical usefulness and motivation to learn (Pribeanu \& Iordache, 2010, Iordache \& Pribeanu, 2011). The analysis of both quantitative and qualitative suggested that further research should include additional variables.

A shortcoming of the evaluation instrument was the lack of variables measuring various aspects related to the perceived utility of specific AR capabilities. Another shortcoming was the limitation to reflective measurement models leaving out formative indicators that could measure specific aspects (Pribeanu, 2012).

\section{Method}

\subsection{Equipment}

The AR platform consists of 4 independent modules organized around a table on which real objects are placed (Wind, Riege \& Bogen, 2007).

An important outcome of the Chemistry scenario is the integration of two categories of real objects: balls and periodic table. Each real object increases the complexity of the scenario with the semantic relationships that could be established between it and other objects in the same category as well as with objects from other categories.

Assigning semantics to a ball by placing it onto a Chemical element on the periodic table creates a feeling of freedom and control for the student who can master the learning process (Pribeanu \& Iordache, 2010). It is well known from the theory of educational games that the 
more complex rules are provided, the more attractive a game is. This is a special source of attraction that creates a strong opportunity for a constructivist approach.

\subsection{Participants and procedure}

A total of 71 seventh grade students (35 boys and 36 girls) tested the Chemistry scenario in a session lasting 30 minutes. They were not familiar with the AR technology.

After testing, the students were asked to answer a questionnaire by rating the items on a 5-point Likert scale. The data was collected in MayJune 2012.

\subsection{Learning goals and tasks}

The learning scenario for chemistry has an introduction and three lessons (Wind, Lamanauskas \& Krivanek, 2008). Each lesson has several exercises. The introductory part is a demo explaining the possibilities of interaction with real and virtual objects in ARTP, the structure of the atom, and the atom layers.

The first lesson aims to explain the basic principles of arranging chemical elements in the periodic table. The exercises consist in placing a coloured ball on the symbols of chemical elements in the periodic table. The ball is augmented with the external layer of electrons and charge of nucleus. The goal is to analyse all (real and virtual) information and to find some regularity in the periods and in the groups.

The learning tasks for the second lesson are: a) to explain the elements involved in creating chemical bonds; b) to know and explain how the atom differs from the molecule; c) to know how to combine molecules and the ionic compounds. The exercises ask to create atoms by placing a coloured ball on a chemical element of the periodic table and to create chemical compounds.

The learning tasks for the $3^{\text {rd }}$ lesson are to explain the elements involved in creating chemical reactions and to know how to combine molecules and the ionic compounds. Each exercise is asking the student to simulate a chemical reaction according to a chemical equation. For example, in the third exercise the student is prompted with the equation " $2 \mathrm{H}_{2}+$ $\mathrm{O}_{2} \rightarrow 2 \mathrm{H}_{2} \mathrm{O}$ ".

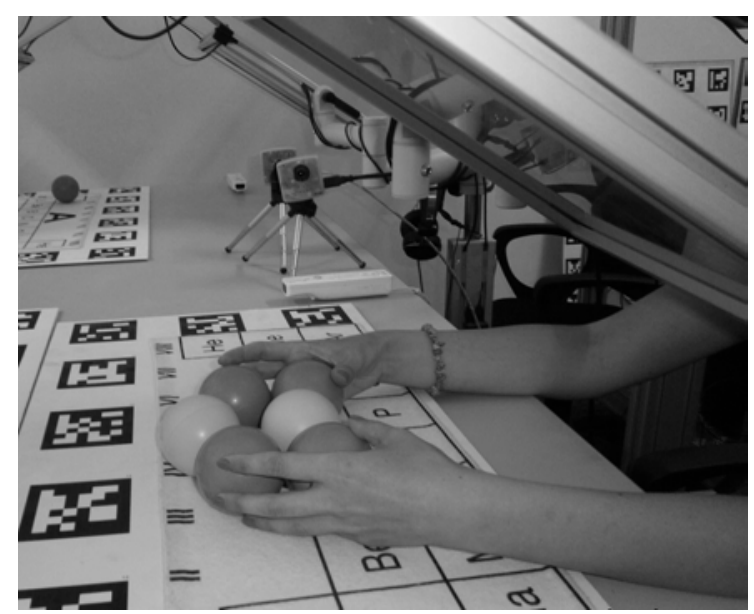

Figure 1. An exercise from the $3^{\text {rd }}$ lesson

In Figure 1 we could see how a student is creating two molecules of water from two molecules of hydrogen (blue balls) and one molecule of oxygen (yellow balls).

\subsection{Questionnaire}

Based on the conclusions drawn from our previous work we started the development of a new evaluation instrument. An internal analysis was conducted to assess the face validity of measurement scales. Then it was administrated to a pilot sample $(\mathrm{N}=71)$. In this paper we are only using a set of 10 items. More details will be given in the next future, after the refinement of the questionnaire.

The questionnaire presented in Table 1 has 10 questions (items). The first 8 items refer to specific capabilities of the ARTP that support understanding and learning of some typical Chemistry concepts. The last two items are measuring two facets of the perceived utility.

Next we will detail the rationale for the first 8 items of the questionnaire.

Q1. Using augmented reality, students can manipulate the virtual $3 \mathrm{D}$ objects in the computer in a simple and intuitive way. As a result, augmented reality has the potential to improve the understanding of the spatial structure of a molecule (Maier et al, 2009). Also Nunez et al (2008) consider that materials' structures are much better understood using 3D models and tangible interfaces.

Q2. Understanding chemistry depends on understanding the spatial structure of the chemical parts. If the 3D understanding of the chemical structures is not given, the students have difficulties understanding certain behaviour of molecules (Maier et al, 2009). 
Interacting with the virtual compounds and structure, students get a better understanding of the fundamental chemistry concepts and structure (Nunez et al, 2008).

Q3. To understand a specific chemical reaction the spatial arrangement of the atoms in a molecule has to be known (Maier et al, 2009). Interactive simulation proved to be an effective tool for the learning process (Pinter et al, 2012).

Q4. Nunez et al. (2008) appreciated that student could learn more and better from hands-on experiences than from traditional lectures. In addition to the visual and auditory senses addressed by computer interfaces, ARTP involve the haptic sense, students manipulating coloured balls with their hands. Woods et al (2004) found that this appeals to students who learn best through kinaesthetic means, fulfilling Gardner's (1993) demand that instructional activities should appeal to different forms of intelligence and learning modalities.

Q5. Some authors (Chien et al., 2010; Dunleavy et al., 2009; Kye \& Kim, 2008) highlight unique affordances for learning of augmented reality such as its capacity to promote kinaesthetic learning tasks ant its support for memory cognitive processes.

Q6. Students participating to an evaluation of an augmented reality application for teaching chemistry (Pribeanu \& Iordache, 2010) found the learning scenario good for testing their knowledge and improving their performance on tests.

Q7. The voice commands in the system described by Sankaranarayanan et al (2003) enables more focus on the model and less on the computer interface. Results from our pervious work also showed that children liked this feature (Iordache \& Pribeanu, 2011).

Q8. Shelton (2003) argued that learners can increase their achievements and satisfaction by enhancing their sense of control through the manipulation of learning contents. Billinghurst (2003) also found that the interaction with the AR content through a tangible interface is enabling an active learning process. Virtual environments also proved to create a feeling of control over the learning process as well as a feeling of ownership over the learning environment (Pribeanu and Iordache, 2010, Niculescu and Thorsteinsson, 2011).

\section{Evaluation Results}

\subsection{Descriptive statistics}

The measures of central tendency and variation are presented in Table 1.

Regarding the first 8 items, the highest mean values got the items Q4 and Q7, confirming that the manipulation of real objects as well as the vocal explanations are well supporting the interaction with ARTP. The mean values of the last two items show that ARTP is increasing both the efficiency (learning with less effort) and effectiveness (better understanding).

\subsection{Correlation analysis}

The main purpose of this study is to explore the possible links between the various capabilities of the ARTP as well as to what extent each of

Table 1 Descriptive statistics

\begin{tabular}{|r|l|r|r|}
\hline No & \multicolumn{1}{|c|}{ Question } & \multicolumn{1}{c|}{ M } & \multicolumn{1}{c|}{ SD } \\
\hline Q1 & The augmentation helps to understand the chemical structure of an atom & 4.44 & .75 \\
\hline Q2 & Building a molecule from atoms helps to understand Chemistry & 4.55 & .77 \\
\hline Q3 & Simulating a Chemical reaction with ARTP helps to understand it better & 4.37 & .83 \\
\hline Q4 & Interacting with colored balls symbolizing atoms is a good idea & 4.61 & .80 \\
\hline Q5 & Using ARTP helps to understand the periodic table & 4.06 & 1.04 \\
\hline Q6 & Performing exercises with ARTP is useful to test my Chemistry knowledge & 4.42 & .75 \\
\hline Q7 & Vocal explanations help interacting with ARTP & 4.61 & .73 \\
\hline Q8 & ARTP creates a feeling of control over the learning process & 4.18 & .92 \\
\hline Q9 & ARTP would help me to learn with less effort & 4.37 & .87 \\
\hline Q10 & ARTP would help me to understand the lesson better & 4.31 & .89 \\
\hline
\end{tabular}


them is contributing to the efficiency and effectiveness of learning with ARTP.

An analysis using Pearson's correlation shows that there are several significant linear relationships between the items Q1-Q8 as well

\subsection{Regression analysis}

In order to explain the contribution of each specific ARTRP capability to the efficiency and effectiveness of the learning process we carried on a multiple regression analysis.

Table 2. Correlation analysis

\begin{tabular}{|c|l|l|l|l|l|l|l|l|l|l|}
\hline Variable & Q1 & Q2 & Q3 & Q4 & Q5 & Q6 & Q7 & Q8 & Q9 & Q10 \\
\hline Q1 & 1 & & & & & & & & & \\
\hline Q2 & $.52^{* *}$ & 1 & & & & & & & & \\
\hline Q3 & $.47^{* *}$ & $.62^{* *}$ & 1 & & & & & & & \\
\hline Q4 & -.02 & -.04 & .07 & 1 & & & & & & \\
\hline Q5 & $.46^{* *}$ & $.39^{* *}$ & $.39^{* *}$ & -.02 & 1 & & & & & \\
\hline Q6 & $.38^{* *}$ & $.31^{* *}$ & $.62^{* *}$ & -.00 & $.50^{* *}$ & 1 & & & & \\
\hline Q7 & .16 & .09 & .20 & $.32^{* *}$ & .01 & .10 & 1 & & & \\
\hline Q8 & $.32^{* *}$ & .10 & .17 & .14 & $.29^{*}$ & $.32^{* *}$ & $.26^{*}$ & 1 & & \\
\hline Q9 & .08 & .19 & $.35^{* *}$ & .1 & $.37^{* *}$ & $.46^{* *}$ & $.30^{*}$ & $.28^{*}$ & 1 & \\
\hline Q10 & $.37^{* *}$ & $.48^{* *}$ & $.46^{* *}$ & -.05 & $.55^{* *}$ & $.47^{* *}$ & $.26^{*}$ & $.47^{* *}$ & $.41^{* *}$ & 1 \\
\hline
\end{tabular}

as between them and the items Q9 and Q10. The correlations are presented in Table 2.

The significant positive correlations between the items $1,2,3$, and $5(\mathrm{p}<1.001)$ shows the links between the three lessons and between them and the introductory part (demo). Lesson 2 is based on the knowledge regarding the structure of the atom while Lesson 3 is based on building molecules from atoms. Both lessons are based on lesson 1 which, in turn, is based on the demo.

The significant positive correlations between each of the first three items and the item Q5 $(p<1.001)$ shows a strong link between understanding the periodic table and performing the exercises.

The correlation analysis shows that there is a significant positive correlation between the items Q4 and Q7 ( $<0.001)$.

As it could be observed, there are several significant positive correlations between the items Q1-Q8 and the last two items (Q9 and Q10). This suggests exploring the influence of specific ARTP features on the efficiency and effectiveness of learning with ARTP. As it could be observed, the item Q4 is only correlated with Q7 which suggests that it is more related to the perceived enjoyment than to the perceived utility.
The analysis was performed using SPSS EXPLORE for evaluation of assumptions and SPSS REGRESSION (standard method).

Results of evaluation of assumptions led to transformation of the variables to reduce skewness, reduce the number of outliers, and improve the normality, linearity, and homoscedasticity of residuals. Data transformation by variable reflection and square root extraction was used.

With the use of a $\mathrm{p}<0.001$ criterion for Mahalanobis distance no multivariate outliers among the cases were found. No cases had missing data, $\mathrm{N}=71$.

\section{Learning with less effort}

A standard multiple regression was performed between "Efficiency" (Q9) as dependent variable and Q3, Q5, Q6, Q7, and Q8 as independent variables.

The independent variables are correlated with the dependent variable Q9. The correlations between the independent variables are not too high. VIF values are all well below 10 (maximum value is 1.851) and the tolerance statistics all well above 0.2 (minimum value is 0.540 ); therefore, we can conclude that there is no colliniarity within our data. The Durbin- 
Watson test value is 1.777 and we can conclude that the residuals are uncorrelated.

Table 3 displays the standardized regression coefficients $\beta$ and their significance, $R, R^{2}$, and adjusted $R^{2}$. Multiple correlation $(R=0.525)$ for regression was significantly different from zero, $\mathrm{F}(5,65)=4.946, \mathrm{p}<0.000$, with $\mathrm{R}^{2}$ at 0.28 . The adjusted $\mathrm{R}^{2}$ value of 0.22 indicates that $22 \%$ of the variability in Q9 is predicted by the independent variables.

Table 3. Regression analysis for Q9

\begin{tabular}{|c|r|r|r|}
\hline $\begin{array}{l}\text { Independent } \\
\text { variables }\end{array}$ & \multicolumn{1}{c|}{ Beta } & \multicolumn{1}{c|}{$\mathrm{t}$} & \multicolumn{1}{c|}{ Sig. } \\
\hline Q3 & .092 & .686 & .495 \\
\hline Q5 & .111 & .900 & .372 \\
\hline Q6 & .287 & 2.000 & .050 \\
\hline Q7 & .236 & 2.107 & .039 \\
\hline Q8 & .041 & .345 & .731 \\
\hline $\begin{array}{l}\mathrm{R}=.525, \mathrm{R}^{2}=.276, \text { Adj. }{ }^{2}=.220 ; \mathrm{F}(5,65)=4.946, \\
\text { Sig.=.001 }\end{array}$ \\
\hline
\end{tabular}

Two variables (Q6, Q7) are significant at $\mathrm{p}<0.05$ level. Q6 is the more important, as indicated by the standardized regression coefficient $(\beta=0.287, p=0.050)$. The size and direction of the relationships suggest that students perceived ARTP as useful for testing Chemistry knowledge and they found the vocal explanations helpful.

\section{Better understanding}

Another standard multiple regression was performed between "Effectiveness" (Q10) as the dependent variable and Q1, Q2, Q3, Q5, Q6, Q7, and Q8 as independent variables.

The independent variables are correlated with the dependent variable Q9. The correlations between the independent variables are not too high which shows that there is no colliniarity. This is confirmed by the values of Tolerance and Variance Inflation Factor (VIF). Cut-off values frequently used are tolerance less than 0.20 or VIF above 10 (Field, 2005). In this study the minimal tolerance value is 0.417 , which is above the cut-off of .20 and the VIF value has a maximum of 2.397. The DurbinWatson test value is 2.198 and we can conclude that the residuals are uncorrelated.

Table 4 displays the standardized regression coefficients $\beta$ and their significance, $R, R^{2}$, and adjusted $\mathrm{R}^{2}$. Multiple correlation $(\mathrm{R}=0.726)$ for regression was significantly different from zero, $\mathrm{F}(7,63)=10.001, \mathrm{p}<0.000$, with $\mathrm{R}^{2}$ at
0.53 . The adjusted $\mathrm{R}^{2}$ value of 0.47 indicates that almost half of the variability in Q10 is predicted by the independent variables.

Table 4. Regression analysis for Q10

\begin{tabular}{|c|r|r|r|}
\hline $\begin{array}{l}\text { Independent } \\
\text { variables }\end{array}$ & \multicolumn{1}{c|}{ Beta } & \multicolumn{1}{c|}{$\mathrm{t}$} & \multicolumn{1}{c|}{ Sig. } \\
\hline Q1 & -.105 & -.948 & .347 \\
\hline Q2 & .284 & 2.374 & .021 \\
\hline Q3 & .103 & .768 & .446 \\
\hline Q5 & .268 & 2.482 & .016 \\
\hline Q6 & .124 & 1.024 & .310 \\
\hline Q7 & .158 & 1.720 & .090 \\
\hline Q8 & .288 & 2.886 & .005 \\
\hline $\begin{array}{l}\mathrm{R}=.726, \mathrm{R}^{2}=.526, \text { Adj. }{ }^{2}=.474 ; \\
\text { Sig.=.000 }(7,63)=10.001,\end{array}$ \\
\hline
\end{tabular}

Three variables (Q2, Q5, and Q8) are significant. The variable Q8 is the more important, as indicated by the standardized regression coefficient $(\beta=0.288, \mathrm{p}=0.005)$. The size and direction of the relationships suggest that the learning effectiveness is well supported by the following ARTP features: building molecules from atoms (Q3), understanding the periodic table (Q5) and creating a feeling of control over the learning process (Q8).

As it could be observed from both analyses, the variables Q1 and Q3 had no significant influence on the dependent variables. A reason could be the relationships between the independent variables. In this respect, a regression analysis having Q3 as independent variable revealed two predictors: Q2 and Q6 (Adj. $\mathrm{R}^{2}=.555, \mathrm{p}<0.001$ ). In a similar way, a regression analysis having Q5 as independent variable revealed two predictors: Q1 and Q6 (Adj. $\mathrm{R}^{2}=.291, \mathrm{p}<0.001$ ).

\section{Conclusion and Future Work}

The results of this study show that by using ARTP the students could better understand the lesson and learn Chemistry with less effort. The multiple linear regressions showed that all ARTP exercises helped students to learn chemistry easier.

The study results revealed four predictors for a better understanding of Chemistry concepts (effectiveness aspect): building molecules from atoms (the implemented interaction paradigm), understanding the periodic table (real object), helpful vocal explanations (multimodal 
interaction), and a feeling of control (constructivist e-learning).

The study also revealed two predictors for learning with less effort (efficiency aspect): performing exercises with ARTP and helpful vocal explanations.

There are inherent limitations of this work since the study is using a relatively small pilot sample $(\mathrm{N}=71)$. In this respect, the study is exploratory. Future work will focus on the refinement of the questionnaire in order to proceed to data collection for a larger sample.

\section{Acknowledgements}

ARTP was developed in the framework of the ARiSE research project, funded under FP6027039. We are grateful to Mrs. Luminița Doicin from Bucharest School Inspectorate for facilitating the collaboration with teachers.

\section{REFERENCES}

1. BALOG, A., C. PRIBEANU, The Role of Perceived E njoyment in the Stud ents' Acceptance of an AR Te aching Platform: A Stru ctural Eq uation Modeling Approach , Studies in Informatics and Control, vol. 19(3), 2010, pp. 319-330.

2. BILLINGHURST, M., Augmented Reality in Education. New Hori zons for Learning, 2003, http://www.newhorizons. org/strategies/technology/billinghurst.htm.

3. CHEN, R., X. WANG, An Empir ical Study on Tangible Augmented Rea lity Learning Space for Design Skill Transfer, Tsinghua Science \& Technology, vol. 13(1), 2008, pp. 13-18.

4. CHEN, Y.-C. A Study of Comparing the Use of Augm ented Reality and Phys ical Models in Chemi stry Education. ACM International Conference on Virtual Reality Continuum and Its Applications, 2006, pp. 369-372.

5. CHEN, C.-M., Y.-N. TSAI, (). Interactive Augmented Reality System for

Enhancing Library Instruction

Computers \& Education 2012, vol. 59, pp. 638-652.

6. CHIEN, C.-H., C.-H. CHIEN, T.-S. JENG, An Inte ractive Aug mented Re ality
System for Learning Anatom y

Structure, Proceedings of International Conference of Engineers and Computer Scientists, 2010, pp. 370-375.

7. DI SERIO, A., M. B. IBÁÑEZ, C. D. KLOOS, Impact of an Augm ented Reality System on Students' Motivation for a Visual Art Cours e. Computers \& Education Journal, 2012, pp. 1-11.

8. DUNLEAVY, M., C. DEDE, R. MITCHELL, Affordances and

Limitations of Imme rsive Participat ory Augmented Reality Simulations for Teaching and Learning . Journal of Science Education and Technology, vol. 18(1), 2009, pp. 7-22.

9. FIELD, A., Discovering Statistics using SPSS. Second edition. SAGE Publications Ltd., 2005.

10. FJELD, M., J. FREDRIKSSON, M. EJDESTIG, F. DUCA, K. BOTSCHI, B. VOEGTLI, P. JUCHLI, Tangible User Interface $f$ or Che mistry Education: Comparative Evaluation and Re-design , CHI '07: Proceedings of the SIGCHI conference on Human factors in computing systems. New York, NY, USA, ACM, 2007, pp. 805-808.

11. GARDNER, H. Frames of Mind: The Theory of Multiple Intelligences, London, William Heinemann, 1983.

12. IORDACHE, D., C. PRIBEANU, Impactul problemelor d e utiliz abilitate asupra utilit ăţii perceput e şi experien ței utilizatorului unui scenariu de înv ățare bazat pe realitate îmb ogățită. Revista Romana de Interactiune Om-Calculator, 4 (Special issue - RoCHI 2011), 2011, pp. 43-48.

13. KAUFMANN, H., Augmented Reality with Geometry Education , Doctoral Thesis: Vienna University of Technology, 2004

14. KYE, B., Y. KIM, Investigation of the Relationship between Media

Characteristics, $\mathrm{Pr}$ esence, Flow and Learning Ef fects in Aug mented R eality based Learn ing, International Journal for Education Media and Technology, vol. 2(1), 2008, pp. 4-14.

15. LIU, W., D. CHEOK, Mixed Reality Classroom - Learning from 
Entertainment. Proceedings of $2^{\text {nd }}$ International Conference on Digital Interactive Media in Entertainment and Arts, Perth, Australia, 2007, pp. 65-72.

16. MAIER, P. TÖNNIS, M. KLINKER G. (2009). Dynamics in Tangible Chemical

Reactions. International Conference on Chemical Engineering - ICCE 2009, Amsterdam, Netherlands.

17. MEDINA, E., Y. CHEN, S. WEGHORST, Understanding Biochemist ry with Augmented Reality. C. Montgomerie \& J. Seale (Eds.) Proceedings of World Conference on Educational Multimedia, Hypermedia and Telecommunications 2007, Chesapeake, VA: AACE, 2007, pp. 4235-4239.

18. NICULESCU, A., G. THORSTEINSSON, Enabling Idea Generation through Computer-assisted Collaborative Learning, Studies in Informatics and Control, vol. 20(4), 2011, pp. 403-410.

19. NÚÑEZ M., R. QUIROS, I. NÚÑEZ, J. B. CARDA, E. CAMAHORT, Collaborative Augmented Reality for Inorganic

Chemistry Education, Proceedings of the 5th WSEAS/IASME International Conference on Engineering Education, July 22-24, 2008, Heraklion, 2008, pp. 271-277.

20. PINTER, R., D. RADOSAV, S.M. CISAR, Analyzing the Impact of Using

Interactive Animations in Teaching International Journal of Computers Communications \& Control, vol. 7(1), 2012, pp. 147-162.

21. PRIBEANU, C., Un mo del formativ de măsurare a valorii $m$ otivaționale a unei aplicații educa ționale bazate pe realitate îmbogățită. Revista Romana de Interactiune Om-Calculator, vol. 5(2), 2012, pp. 13-18.

22. PRIBEANU, C., Specification and Validation of a Second Order Formative Index to Evaluate the Ergonom ic Quality of an AR-ba sed Educational Platform. International Journal of Computers, Communication and Control, vol. 7(4), 2011, pp. 720-731.
23. PRIBEANU, C., A. BALOG, D. D. IORDACHE, Formative User-c entered Usability Evaluation of an Augmented Reality Educational Syst em, Proceedings of ICSOFT 2008 - The Third International Conference on Software and Data Technologies, Porto 5-8 July, INSTICC. 2008, pp. 65-72.

24. PRIBEANU, C., D. D. IORDACHE, From Usability to User Experience: Evaluating the Educatio nal and Motivational Value of an Aug mented Reality Scena rio. Affective, I nteractive and Cognitive Methods for E-Lear ning Design: Creating an Optimal Education Experience, Tzanavari E., Tsapatoulis N. (Eds), IGI-Global, 2010, pp. 244-259.

25. SANKARANARAYANAN, G., S. WEGHORST, M. SANNER, A. GILLET, A. OLSON, Role of Haptics in Teaching Structural Molecular Biology

Proceedings of Symposium on Haptic Interfaces for Virtual Environment and Teleoperator Systems (IEEE HAPTICS’03), 2003, pp. 363-366.

26. SHELTON, B. E., How Augmented Reality Hel ps Students Learn Dynamic Spatial Relationships . PhD Thesis, University of Washington, 2003.

27. WIND, J., K. RIEGE, M. BOGEN, Spinnstube ${ }^{\circledR}$ : A Seated Augmented Reality Display S ystem, Proceedings of IPT-EGVE - EG/ACM Symposium, 2007, pp. 17-23.

28. WIND, J., V. LAMANAUSKAS, J. KRIVANEK, Deliverable D4.2:

Description of Less ons, Electr onic Content and 3D Models . ARISE project, FP6-027039, 2006.

29. WOODS, E. et al, Augmenting the Science Centre and Museum Experience. Proceedings of Graphite 2004, ACM, 2004, pp. 230-236. 